\title{
19. Distributed agency in living labs for sustainability transitions
}

\author{
Anil Engez, Paul H. Driessen, Leena Aarikka-Stenroos and \\ Marika Kokko
}

\section{INTRODUCTION}

The notion of sustainability is closely related to the impact of the production/consumption habits on the environment and ecosystems, and highlights the urgency for the efficient use of raw materials and conservation of nature (Markard et al. 2012). Consequently, sustainability is one of the main principles of the circular economy that aims to convert the linear take, make, dispose models into more circular ones, with the goal of maximizing the utilization of resources (Geissdoerfer et al. 2017).

There is an urgent need for more sustainable living and urban governance as natural resources are gradually being depleted and are deteriorating as a result of linear production/ consumption patterns, which threatens our well-being (Bifulco et al. 2016; Liedtke et al. 2012; Voytenko et al. 2016). One of the reasons for the deterioration of natural resources is the insufficient recycling of the nutrients contained in municipal wastewaters and in organic side streams such as biowaste or manure from domestic animals (Malila et al. 2019). Globally, sustainability challenges in many domains are increasing (Geissdoerfer et al. 2017). On the other hand, the shift to the use of renewable energy from fossil fuels has already begun in all parts of the world, aiming for decarbonization, and many sustainability projects have been set up as a response to accelerate the sustainability transition. This brings up the issue of how several actors work together towards environmental sustainability goals. Sustainability transitions involve a broad range of actors who work towards a shared goal in a coordinated way (Markard et al. 2012), thus most sustainability transitions rely on some form of distributed agency.

Agency is defined as "the relation between a person and a course of action and its effects" (Enfield and Kockelman 2017, p. 7). Distributed agency represents the actions of a group or multiple people as an interactive emergence (Garud and Karnøe 2005; Enfield and Kockelman 2017). The concept of distributed agency fundamentally adopts a broad perspective on sustainability transitions and emphasizes that, although some actors work independently from each other with different motivations and interests, their actions result in a shared benefit to all and to society (Garud and Karnøe 2005).

Living labs are one of the ways to support the sustainability transition by employing an experimental approach to testing different solutions for various urban challenges (Voytenko et al. 2016). Living labs can be considered as (i) a research methodology, where a user-centric approach is taken for evaluating complex solutions, or (ii) physical sites, e.g. households, cities, villages, rural areas or industrial sites, where innovative approaches are tested. In both cases the solutions and approaches are tested in real-life contexts (Dell'Era and Landoni 
2014). In this chapter, the focus is on a physical living lab located in a city district, i.e. an urban living lab.

The urban living lab concept emphasizes the involvement of authorities, companies, researchers and users who test new products, services, processes and systems which can strengthen the sustainable urbanization efforts in specific areas within cities while taking into account the environmental issues and lifestyles (Bulkeley et al. 2016). By bringing public and private actors together in an urban living lab, the stakeholders of a project can experiment with mechanisms of the distributed agency. Proactive networking among the actors is a key success factor in an urban living lab, which is due to the need to utilize stakeholders for knowledge and resource sharing and awareness creation (Aarikka-Stenroos et al. 2014). An urban living lab can lead to a new way of urban planning through the implementation of novel processes (Engez et al. 2021). Urban areas being built from scratch present opportunities to apply innovative infrastructure, to test and validate solutions, to conduct longitudinal research studies, and to co-create innovations while engaging various stakeholders (Juujärvi and Pesso 2013).

Previous research has acknowledged the contribution of particular actors and activities to sustainability transition (Bifulco et al. 2016; Bulkeley et al. 2016; Koistinen et al. 2020), and our study elaborates the relevance of distributed agency in living labs in terms of the joint efforts of actors on maximization of resource utilization in urban management. Our approach draws attention to the impact of the involved stakeholders on shifting the mindsets towards inclusivity, empowering, experimentation and transparency for increased sustainability. This chapter seeks answers to two questions: first, we explore how the sustainability agency is formed and distributed through a living lab setting; second, we seek answers to how the distributed agency improves sustainability in cities. To support the discussion, we use an example case of distributed agency in a work-in-progress city district that is promoted as a smart and sustainable future neighborhood, positioned as an urban living lab. The activities of various living lab actors on sustainable city development, urban governance, nutrient recycling, and energy production were examined to study the concept of distributed agency at the city district level.

This chapter is structured as follows: following this introduction, the concept of distributed agency, living labs in sustainable city development, and characteristics and building blocks of urban living labs are discussed to build the theoretical background of the study. In the fourth section, the research methodology is presented. In the fifth section, activities of the living lab actors that improve the sustainability in the district are discussed through the lens of distributed agency. The final section concludes the chapter and presents theoretical contribution, practical implications and the opportunities for future research.

\section{DISTRIBUTED AGENCY}

The concept of agency involves two key elements: flexibility and accountability (Enfield and Kockelman 2017). Flexibility refers to the freedom to display certain behavior. The behavior could be taking a decision, performing an activity or responding to another actor. Flexibility implies that an actor has a certain level of control over the behavior (Enfield and Kockelman 2017). Accountability refers to the evaluation of the outcomes of the behavior. This evaluation could be executed by the actor itself or by external actors. Through accountability, actors are held responsible for their behavior. In the context of sustainability, the evaluation would 
refer to the degree to which sustainable goals have been met. However, actors could also hold goals they want to achieve for themselves. Distributed agency refers to the phenomenon where multiple actors - with their own goals and while keeping their independence - work collectively towards a common goal (Sprong et al. 2021). "With distributed agency, multiple people act as one" (Enfield and Kockelman 2017, p. 9). Technology entrepreneurship is such a joint process (Garud and Karnøe 2003): agency in an entrepreneurial or innovative context is often distributed. The concept of distributed agency implies that flexibility and accountability are shared. Therefore, the key elements of distributed agency are distributed flexibility and distributed accountability.

Distributed flexibility means that all actors remain independent, fulfill their own role, using the resources they have at hand. Distributed accountability means that all actors are collectively subject to evaluation. The behavior is seen to be that of the group and succeeding or failing to achieve the common objective is evaluated on that level. This is very much the case in the context of sustainability, which is typically evaluated on a systems level. Distributed flexibility and distributed accountability require some level of improvisation, bricolage, and effectuation (Garud and Karnøe 2003).

\section{URBAN LIVING LABS AS DRIVERS OF SUSTAINABILITY TRANSITION}

The living lab approach is presented as a research methodology for identifying and testing the real-life solutions that are driven by the users and developed through public-private partnerships (Niitamo et al. 2006). Living labs fundamentally have three main characteristics that build up their foundation. First, living labs take place in a forum, a physical location or collaborative virtual networks (Niitamo et al. 2006). Second, they involve real-life experiments, interactions, co-creation, prototyping, testing, and validation while engaging diverse actors such as users, citizens, researchers, companies, and authorities employing an open-innovation mindset (Bergvall-Kareborn and Stahlbrost 2009; von Hippel 2005). Third, they aim to improve or develop a solution, innovation, product, service, technology, infrastructure, or system that would lead to social, economic, and/or environmental value creation (Leminen et al. 2012). The stakeholder engagement aspect of living labs emphasizes the collaborative atmosphere that brings science, policy, business, and civil society together (Edwards-Schachter et al. 2012). Therefore, a living lab approach considers the agency as the complementing actions of the living lab actors that can drive a transformation of socio-technical systems such as energy supply, water supply, or transportation (Markard et al. 2012). Although such transformation typically evolves over long timespans, living labs can be considered as new platforms for distributed agency where socio-technical transitions are accelerated due to the involvement of the stakeholder network in the experiments and co-creation.

As a method of urban governance, local governments have been encouraging partnerships among public organizations, government, and industry in their approaches to address urban challenges (Couch et al. 2003). Living labs are a form of basic coordination, where a set of actors is not governed by control or rewards, but by a minimal level of governance instead (Manser et al. 2016). The governance arrangements in living labs vary and are reported to be "more contingent than controlled" (Bulkeley et al. 2018). The multiple actors in living labs come from different organizations and, thus, they cannot be directly managed but rather 
motivated by the coordinator of the living lab (Leminen and Westerlund 2012). The publicprivate-people partnerships (4P concept) among stakeholders are brought up to be the building blocks of the living labs that are composed of heterogeneous actors who get involved in co-creation, exploration, experimentation, and evaluation activities (Westerlund and Leminen 2011). Apart from the roles of the other type of actors, users have a distinct and important role in living labs, which makes the approach more experimental (Leminen et al. 2012).

The application of living labs in urban areas aiming for sustainability has been studied by several scholars. In these studies, the urban living lab (ULL) term has been used and it has been discovered that, with the implementation of the living lab approach in urban areas, rapid social, technological, and economic transformation can be achieved (Voytenko et al. 2016). ULLs focus on issues of planning, governance, infrastructure, resilience, consumption, behaviors, and lifestyles (Voytenko et al. 2016), and they work as a platform for different kinds of interventions, trials, and demonstrations in a city area that brings together various actors, which would contribute to the development of the region (Bulkeley et al. 2016). The developments accomplished in living labs can be scaled up through wider adoption by stakeholder involvement and can eventually become a widespread application or even a radical innovation through the measures taken by policy makers (Geels 2002; Ingstrup et al. 2020).

\section{METHODOLOGY: RESEARCH DESIGN, CASE AND DATA}

We explore the concept of distributed agency in an ULL case from Finland. Our case focuses on a living lab that aims to contribute to the development of a work-in-progress city district, Hiedanranta, which involves research projects, business activities, and citizen participation to create and develop the district while employing the principles of sustainability (Ingstrup et al. 2020). The projects and business activities started in the area with the objective of building a smart and sustainable future city district that produces more resources than it consumes. Hiedanranta living lab, which is located in the city of Tampere is chosen as the case study, as it provides a distinctive base to study distributed agency through public-private-people partnerships (4P concept) and includes a multiple stakeholder setting comprising a governmental body, associations, private firms, residents, and research institutes. Hiedanranta living lab enables testing of different solutions, applications, and infrastructures, as the district is in the creation phase of becoming a proper livable city district. Hiedanranta living lab employs an experimentation approach in urban settings through stakeholders who pursue a sustainable city district.

We use the Hiedanranta living lab as an instrumental case study (Mills et al. 2010), as the ULL acts as a basis from which to advance the understanding of the distributed agency concept. The case relies on qualitative research design and multi-sourcing strategy in data gathering. We have captured the case and examined distributed agency among the actors of the Hiedanranta living lab through interviews with key stakeholders, observation, and broad secondary data. As the case includes individual and collaborative actions for sustainability, our methods enabled investigating those individual actors and their involvement. The case encompasses businesses by including three companies (focusing on biochar production, vertical farming, and production of dry toilets) established within the living lab. The case also comprises five sustainability projects in Hiedanranta (see Table 19.1): the projects were 


\section{Table 19.1 Selected sustainability projects in Hiedanranta and related stakeholders}

\begin{tabular}{|c|c|c|}
\hline Project & Scope & Stakeholders \\
\hline 1. NutriCity & $\begin{array}{l}\text { Reducing the amount of nutrient leakage into the Baltic } \\
\text { Sea by recycling nutrients such as phosphorus and nitrogen } \\
\text { through decentralized sanitary solutions. }\end{array}$ & $\begin{array}{l}\text { Ministry of the Environment, City of } \\
\text { Tampere, Tampere University of Applied } \\
\text { Sciences (TAMK), Finnish Environment } \\
\text { Institute (SYKE), residents, Global Dry Toilet } \\
\text { Association of Finland, dry toilet company }\end{array}$ \\
\hline 2. UNaLab & $\begin{array}{l}\text { Developing stormwater management systems such as } \\
\text { biofilters to treat nutrient-rich seepage waters from the } \\
\text { old landfill in Hiedanranta. Tampere is one of the three } \\
\text { pioneer cities of UNaLab (Urban Nature Labs), along with } \\
\text { Eindhoven and Genoa. }\end{array}$ & $\begin{array}{l}\text { European Union, City of Tampere, Technical } \\
\text { Research Centre of Finland (VTT), residents, } \\
\text { Biochar company }\end{array}$ \\
\hline 3. Leväsieppari & $\begin{array}{l}\text { Recovery and recycling of nutrients in wastewater, using } \\
\text { algae. The aim is to reduce water pollution and to utilize } \\
\text { algae-bound nutrients. }\end{array}$ & $\begin{array}{l}\text { Ministry of the Environment, Tampere } \\
\text { University, Finnish Environment Institute } \\
\text { (SYKE), Häme University of Applied Sciences } \\
\text { (HAMK), University of Helsinki, Vanajavesi } \\
\text { Center }\end{array}$ \\
\hline 4. Hierakka & $\begin{array}{l}\text { Convincing authorities, the food industry and farmers of } \\
\text { the functionality of urine as a fertilizer and changing the } \\
\text { attitude towards the use of urine fertilizers. }\end{array}$ & $\begin{array}{l}\text { Ministry of the Environment, City of Tampere, } \\
\text { Tampere University of Applied Sciences } \\
\text { (TAMK), residents, Global Dry Toilet } \\
\text { Association of Finland, dry toilet company }\end{array}$ \\
\hline 5. Kivireki & $\begin{array}{l}\text { Exploring the potential of professional urban farming, } \\
\text { finding solutions to promote local nutrient cycles in cities } \\
\text { (e.g. through biowaste, separately collected urine) and } \\
\text { examining the associated threats of processing nutrients. }\end{array}$ & $\begin{array}{l}\text { European Union, City of Tampere, Tampere } \\
\text { University of Applied Sciences (TAMK), } \\
\text { residents, Global Dry Toilet Association of } \\
\text { Finland, vertical farming company }\end{array}$ \\
\hline
\end{tabular}

chosen based on their potential to improve environmental sustainability, and particularly nutrient recycling in the region, which are the ultimate mutual goals of the involved actors.

In the study, the primary data source is qualitative interviews which were conducted with managers of the three living lab firms, two city development project managers from the municipality, one project manager from an association, and with two researchers who study nutrient recycling technologies. In total, eight people were interviewed in semi-structured form and all the interviews were recorded and transcribed with the interviewees' consent. The gathered data from the living lab firms is used to analyze their operations associated with the district development activities in Hiedanranta, and knowledge and material sharing practices among them. The data from the researchers and association is used to analyze the approaches that are mainly used for the recovery and utilization of nutrients. Lastly, the data from the municipality is used to analyze the urban governance and stakeholder engagement approaches that support the emergence of collaborative innovation in cities.

The analysis is done by assessing the stakeholder activities in the living lab setting, particularly related to nutrient recycling activities, and by comparing the interviews with each other and with news articles to verify the consistency of the information. Therefore, triangulation was employed for the cross-verification of the data and for capturing different dimensions of the phenomenon. In our analysis, we focus on the nutrient recycling projects in the Hiedanranta living lab due to their substantial potential to increase the environmental sustainability; thus, the impact of other types of projects in Hiedanranta has been excluded in this study. The transcribed interviews were thoroughly read, and important statements were highlighted to point out valuable information. After the theoretical framework of the study 
was created, the activities, interactions, and approaches of living lab actors were identified. Distributed agency is studied by using two elements to realize the impact of actors on sustainability: distributed flexibility and distributed accountability. We use the distributed flexibility element to analyze the aspects and acts of actors that enable or hinder the collaborations in the living lab. Distributed flexibility shows that all actors display behavior that fits with their resources and roles. The second element, distributed accountability, is used to demonstrate how the individual goals are attained and how the mutual goal of sustainability is achieved at the city district level. From our analysis, a conceptual framework was developed to depict the key components of the distributed agency in the sustainable ULLs.

\section{DISTRIBUTED AGENCY AMONG LIVING LAB ACTORS}

In the selected sustainability projects in Hiedanranta living lab, we analyze the two key elements of distributed agency, which are distributed flexibility and distributed accountability. In the next three subsections, we discuss three groups of actors (public sector and government actors, market actors, and research institutes) and explain how they are flexible in their activities and have freedom to perform activities according to their own goals and interests. In the fourth subsection, we discuss the distributed accountability in relation to particular sustainability goals. In the last subsection, we summarize the distributed agency in Hiedanranta living lab. The actors, actor types, projects they are involved in, and their roles are listed in Table 19.2 to demonstrate the distributed flexibility.

\section{Distributed Flexibility of Public Sector and Government Actors}

The Hiedanranta living lab offers the public sector and government actors a platform to fulfill their own roles, based on their own goals. The Hiedanranta living lab was created by the municipality of Tampere. Changing the way cities use resources, preventing the overuse of natural resources, and creating a neighborhood that produces more resources than it consumes are the visions of resource efficient Hiedanranta. These visions were of utmost importance when creating the plan of the Hiedanranta area and when searching for local businesses in 2015 for the development of the city district. The municipality contributes to the governance of Hiedanranta by initiating and enabling development projects, discussing the development projects in the board meetings of the city to cooperate with decision makers, bringing stakeholders together, supporting the companies for their innovation activities, and involving users and citizens in the events for the co-creation of sustainable solutions. According to the director of the Hiedanranta development project, it is beneficial to create demonstration areas for the public and for decision makers to demonstrate how the development projects are progressing.

When developing Hiedanranta to accommodate 25,000 new inhabitants in the upcoming years, meeting with people and getting their ideas to test the viability of the solutions provide useful insights for the city developers. In order to increase the citizen involvement in the development of Hiedanranta, organizing events such as festivals, theater shows, or concerts proved to be more effective than city planning meetings for receiving feedback from residents. The advantage of organizing such events is to reach people that cannot be reached by organizing city planning meetings. Apart from the citizen involvement in the development of Hiedanranta, the municipality provided buildings for low prices to small businesses such as 
Table 19.2 Distributed flexibility in five sustainability projects in Hiedanranta

\begin{tabular}{|c|c|c|c|}
\hline Actors & Actor type & Project(s) & Role \\
\hline Ministry of the Environment & $\begin{array}{l}\text { Public sector and } \\
\text { government }\end{array}$ & $1,3,4$ & Providing funding and guidelines for the projects \\
\hline European Union & $\begin{array}{l}\text { Public sector and } \\
\text { government }\end{array}$ & 2,5 & Providing funding and guidelines for the projects \\
\hline City of Tampere & $\begin{array}{l}\text { Public sector and } \\
\text { government }\end{array}$ & $1,2,4,5$ & $\begin{array}{l}\text { Providing facilities to enable experimentation and/ } \\
\text { or providing expertise and resources on project } \\
\text { management }\end{array}$ \\
\hline Tampere University & Research institute & 3 & Conducting research and experiments \\
\hline $\begin{array}{l}\text { Tampere University of Applied } \\
\text { Sciences (TAMK) }\end{array}$ & Research institute & $1,4,5$ & Conducting research and experiments \\
\hline $\begin{array}{l}\text { Finnish Environment Institute } \\
\text { (SYKE) }\end{array}$ & Research institute & 1,3 & Conducting research and experiments \\
\hline $\begin{array}{l}\text { Technical Research Centre of } \\
\text { Finland (VTT) }\end{array}$ & Research institute & 2 & Conducting research and experiments \\
\hline $\begin{array}{l}\text { Häme University of Applied } \\
\text { Sciences (HAMK) }\end{array}$ & Research institute & 3 & Conducting research and experiments \\
\hline University of Helsinki & Research institute & 3 & Conducting research and experiments \\
\hline Vanajavesi Center & Foundation & 3 & $\begin{array}{l}\text { Creating an active network of actors for the } \\
\text { improvement of lakes and rivers }\end{array}$ \\
\hline Residents & User & $1,2,4,5$ & $\begin{array}{l}\text { Participating in the testing and providing feedback for } \\
\text { the usage phase of the solutions }\end{array}$ \\
\hline $\begin{array}{l}\text { Global Dry Toilet Association } \\
\text { of Finland }\end{array}$ & Industry association & $1,4,5$ & $\begin{array}{l}\text { Promoting ecological sanitation and communicating } \\
\text { benefits of nutrient cycles }\end{array}$ \\
\hline Biochar company & Company & 2 & Producing biochar material and district heating \\
\hline Vertical farming company & Company & 5 & $\begin{array}{l}\text { Participating in the experiments by testing the urine } \\
\text { fertilizers }\end{array}$ \\
\hline Dry toilet company & Company & 1,4 & Providing the equipment for the collection of urine \\
\hline
\end{tabular}

artisans who are currently running their operations in Hiedanranta, which is an example of how a city can support the transformation of the district into an active and productive area.

Many interesting and important projects in Finland have received funding from the Ministry of the Environment of Finland, which has been one of the active actors that promote the conservation of nature by initiating nutrient recycling projects to improve the ecological status of the Archipelago Sea and reduce eutrophication. The projects they funded in Hiedanranta tackle the issues of environmental pollution, depletion of natural resources, wastewater and sludge treatment, and the threat of rising fertilizer prices in the future.

\section{Distributed Flexibility of Market Actors}

In this study, the market actors refer to the companies that have active operations in Hiedanranta living lab and the residents of the city who participate in the development activities in the area. In the living lab, the companies proceed towards their own goals that coincide with the goals of Hiedanranta. The residents contribute to the development of the area by participating in the projects and sharing their requests about their future living environments with city officials.

One of the companies operating in the area has been active in producing biochar using a pyrolysis process, which takes place through the burning of the woodchips in an oxygen-free 
environment under high temperatures $\left(\sim 600^{\circ} \mathrm{C}\right)$ in order to provide the highest carbon content possible. Due to the high temperatures generated, the pyrolysis process produces syngas and pyrolysis oil, which are used to provide heating energy in the area. The produced biochar can be used as a growth medium in agriculture to grow organic foods, as it enhances plant growth and crop yield by storing nutrients.

An example where the biochar products are used include the UNaLab project, where stormwater management systems are developed to biofiltrate the nutrient-rich leachate from an old pulp mill landfill to prevent it from flowing into the lakes in the area. In the project, biochar along with peat and clay are used for the treatment of water that comes out from a contaminated land. The residents act as informant, tester, and designer in the project.

Due to the harsh winter conditions in Nordic environments for growing food, and due to the unavailability of the land area for growing sustainable food in cities, indoor hydroponics can be considered as a method for crop production. The vertical farming company located in Hiedanranta is specialized in producing strawberries and takes part in sharing and recycling practices in the area, such as using fertilizers made from urine for plant growth, in collaboration with the researchers. The company uses the biochar as a growth medium in its hydroponic systems. It also utilizes the $\mathrm{CO}_{2}$ that is generated in the biochar production facility. The $\mathrm{CO}_{2}$ is transferred through a piping system that was built between two facilities and it is used in the plant growth. The facility uses software that optimizes over 20 parameters for smart resource consumption in order to eliminate waste. The software also creates and utilizes plant growth pattern data that is available to all the farmers worldwide and shares the best practices. In addition to these applications, future plans include processing of local biowaste in a biogas plant in the area and using the nutrient-rich byproduct (sludge) as a fertilizer for plants in the farming facility. The solutions are implemented to create a zero-waste community.

For the proper collection of toilet waste for its further utilization as a fertilizer product, a company takes part in providing the equipment, such as source-separating dry toilets, in the premises in the Hiedanranta area. The pilot of the dry toilets has been designed and implemented in the event venue Kuivaamo, which is currently the largest facility in the area that organizes events for up to 1000 people. The residents act as temporary inhabitants of the area by attending events that take place in the event venue Kuivaamo. The dry toilet waste that is collected in the venue is later composted. The produced compost contains mainly phosphorus and nitrogen, which has been tested and approved for fertilizer use by Finnish authorities. It has been tested in the vertical farming facility in Hiedanranta and in other agricultural fields.

\section{Distributed Flexibility of Research Institutes}

The living lab environment provides a platform and more room for experimentation for researchers to develop breakthrough innovations. It also makes it easier to cooperate with other types of actor due to the open-innovation principle of living labs, which enables the development to progress faster. In Hiedanranta living lab, research has been done on the utilization of urine (collected from source-separating dry toilets) in fertilizer production, recovering nutrients from urine by growing micro-algae in a pilot pond, energy efficient food production by encouraging community gardening, and on decentralized (local) sanitary solutions aiming at nutrient recycling.

The NutriCity project emphasizes the improvement of centralized wastewater treatment systems with decentralized local solutions e.g. to collect the urine directly from 
source-separating dry toilets. As part of the Hierakka and Kivireki projects, researchers encourage the adoption of urine fertilizers in large-scale applications. In the projects, local farmers who tested urine fertilizers were able to see their positive effects. The data generated in the studies was a means to promote the reuse of nutrients and urine fertilizers, encouraging farmers, authorities and policy makers to take action towards making this a widespread practice. However, the required infrastructure for the collection and transportation of urine needs more development and push from the regulators. In this sense, living labs can act as test beds for developing the infrastructure and testing new applications.

In the first demonstration of the micro-algae cultivation plant in Hiedanranta, researchers from Tampere University studied the growth of algae and their capability to capture nutrients from source-separated urine. In addition to fertilizers, some examples of commercially viable end products of micro-algae cultivation may include health food supplements, pigments used as fish feed, cosmetic products, and omega-3 fatty acids. The organic materials that micro-algae contain can be used for biodiesel production, even though this is not the first commercial application to consider due to the current affordable gasoline prices and the high costs of micro-algae cultivation.

\section{Distributed Accountability}

All the actors identified in Table 19.2 have individual goals. For instance, companies want to develop sales, local government wants to develop the district, and research institutes want to develop state-of-the-art knowledge and technologies. However, sustainability goals are often the same both for the living lab as a whole and for the individual actors: to make cities and communities sustainable, to build resilient infrastructure to foster innovation, and to preserve aquatic ecosystems. Accountability concerns the actions of the public sector and government actors, market actors, and research institutes, which is linked to three main activities: governance, technology development and implementation, and research, respectively. We see these activities as the essentials of the sustainability transition that requires effective governance approaches in urban management, timely technology development to respond to the needs, and progress in research to discover new methods, technologies, and approaches to coping with urban challenges. The governance in Hiedanranta living lab is not strictly controlled at present and includes, for example, gathering actors interested in sustainability in one place, encouraging collaboration between the actors, and enabling market development and piloting of technologies. However, in the future the governance should become stricter, when, for example, certain technologies are chosen to be used in the city district based on the current pilots and activities.

Collaboration in Hiedanranta can be seen in a few cases, where the actors are accountable towards each other. For example, heating energy produced in the biochar facility is used to heat the event center Kuivaamo and other buildings in Hiedanranta. The biochar is used as biofiltration material in stormwater management systems in the area and as a growth medium for plants that are grown in the vertical farming facility. The source-separating toilets in Kuivaamo provide the urine to be studied in the research projects that could not be executed if this type of waste stream was not available. To achieve sustainability in nutrient recycling in Hiedanranta, the City of Tampere operates dry and vacuum toilets, and needs researchers and companies to treat the waste and to find future solutions for the city district. The research units and companies have a unique opportunity to study nutrient recovery from this kind of 
material, since there is no other place in Finland that would offer these waste streams with such big quantities. The results show, in Hiedanranta living lab, how each actor has the flexibility to fulfill its own role, yet still can be held accountable for sustainability goals.

\section{Summary of the Distributed Agency in Hiedanranta Living Lab}

The analysis of the activities in Hiedanranta has demonstrated that in the living lab environment, the sustainability agency is distributed among citizens, businesses, researchers, and the municipality for the transformation of the city district into a sustainable setting. The actors have a shared motivation for using the resources in the city district in the most efficient way, which has led to the alignment of goals and initiation of various projects with a sustainability mindset (Ingstrup et al. 2020). Hiedanranta living lab hosts nutrient recycling experiments and facilitates cooperation among businesses and research organizations to share knowledge and expertise. Getting feedback for potential improvements from all the stakeholders such as residents, experts in city planning, architecture, building, and maintenance is inevitable, as Hiedanranta living lab employs an open-innovation mentality and provides an opportunity for ideation and sharing.

\section{CONCLUSIONS}

Distributed agency improves sustainability in cities by enabling different individuals and organizations to work towards a collective goal. To achieve the collective goal of increasing sustainability in the city district, particular activities need to be performed, which include optimization of resource use for the mitigation of carbon emissions, increasing the utilization of waste and side streams in business operations, improving the daily lives of residents through integration of sustainable solutions, performing sustainable business operations, and conducting research and development activities for the exploration of sustainable innovations and solutions to respond to urban challenges. In this context, living labs not only provide the physical location for facilities that enable co-creation activities, but also provide the mentality of open-innovation and stakeholder engagement for those who are part of the living labs, which boosts value maximizing closed loop collaborations.

We argue that individuals have flexibility to perform certain actions and behaviors according to their own agenda. Eventually, what matters for the sustainability transition will be the contribution of these individuals to the areas of governance, technology development, and research, which they will be accountable for. To get the full benefit of the distributed agency, the results of the governance, technology development, and research activities should be evaluated collectively to see if the whole system has succeeded and if the goals are met.

While ULLs are located, for example, in a certain city district or village, the results of the living lab approach can often be transcribed into similar locations where new urban areas are being built. It's worthwhile mentioning that not all the actors (especially governmental actors) might be open to the experimentation approach that urban living labs adopt to transform an urban area. However, in the Hiedanranta living lab, the municipality supports the urban development by being an active promoter of the experimentation approach that has been sought to change the overall landscape of the innovation activities in the city. 


\section{Theoretical Contribution}

Our study shows that living labs create a context for distributed agency, as they combine shared flexibility and shared accountability, and that this enables actors to jointly pursue sustainability. In other words, living labs are a way to organize for distributed agency, which can help achieving sustainability goals. This study provides a hands-on approach to urban development and urban living lab literature (Voytenko et al. 2016) by examining the aspects and actions that enable collaborations in living labs. It introduces a new smart city district as an enabler-driven living lab to the researchers who are interested in developing the knowledge in this area (Leminen et al. 2012). It introduces ways to utilize the resources in a work-in-progress city district that aims to apply sustainable urban management methods contributing to a circular economy (Bulkeley et al., 2016). It clarifies how the sustainability agency is distributed among public sector and government actors, technology companies, academic researchers, and residents. The individual and mutual acts of these actors are displayed in the conceptual framework (Figure 19.1) of distributed agency in sustainable living labs.

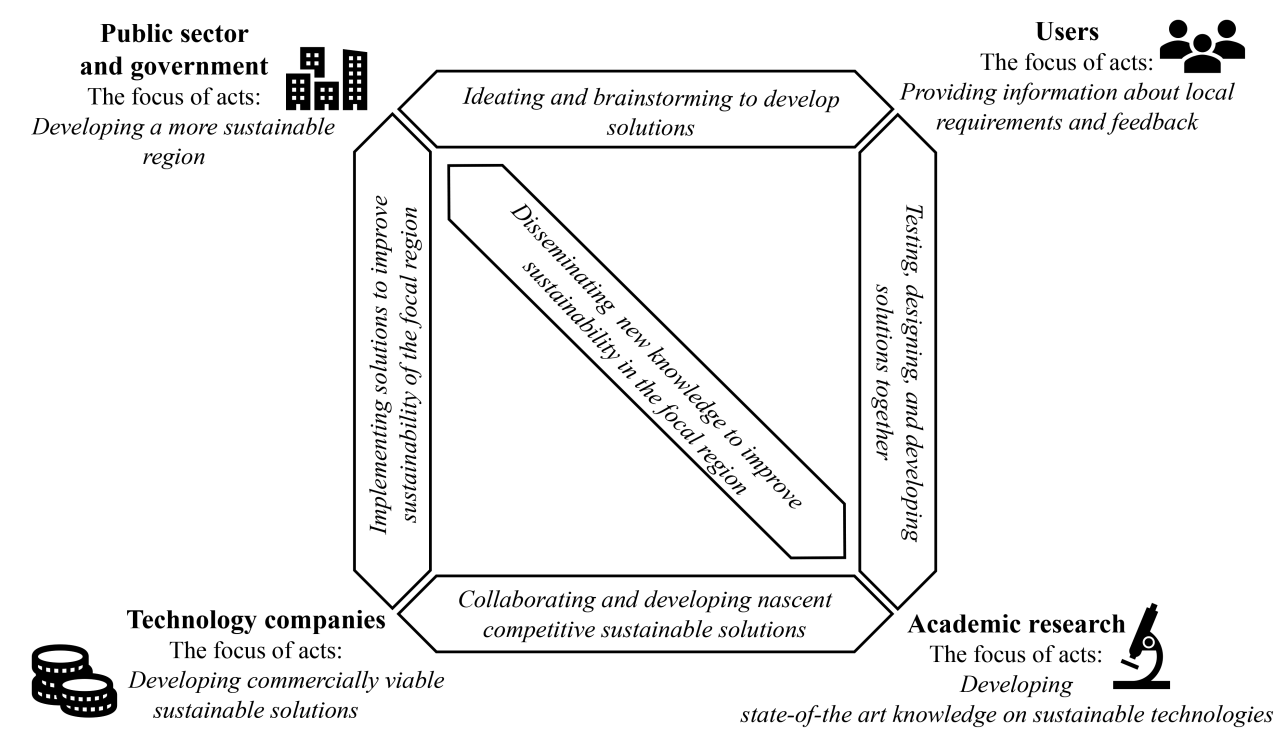

Figure 19.1 Individual and mutual acts of living lab actors

\section{Practical Implications}

Our chapter on distributed agency in sustainable living labs suggests practical implications on how to manage collaborations between diverse actors towards a mutual goal of sustainability. In the big picture, our study shows how a living lab approach can be beneficial for the involved actors (see Figure 19.1), as the municipalities can benefit from supporting small and medium-sized enterprises and researchers that are involved in living labs regarding the sustainable development of a city district. Our study uncovers the positive impact of distributed agency by demonstrating the collaboration between different types of actor, which results in 
collective learning and reaching the mutual goal. Furthermore, our conceptual model shows synergies between involved actors and these can be used as motivational drivers when engaging other actors to include in collaborations. However, we believe that distributed accountability also highlights a relevant pragmatic issue: all actors need to be aware of other actors' success points, otherwise the mutual goal cannot be reached.

\section{Future Research}

Our study builds avenues for future research themes and related research questions, which are suggested next.

\section{Actor diversity in collaborations, distributed agency and multi-actor settings}

What are the positive and negative sides of the actor diversity when pursuing sustainability? How to steer collaborations? What kind of boundary objects or collaboration methods can be used in generating a better understanding among diverse actors to facilitate distributed flexibility and distributed accountability?

\section{Sustainable (urban) living labs and their diversity}

What are the differences between small- and large-scale living labs with regard to collaborations? Further examination of actor perspectives on sustainability would improve the understanding on how the sustainability agency is distributed. Including the residents in the study and employing a survey methodology might provide useful insights on user perspectives on the feasibility and acceptability of new solutions, such as the adoption of decentralized sanitary solutions for nutrient recycling vs. less sensitive sustainable solutions such as shared vehicles in urban settings.

\section{ACKNOWLEDGMENTS}

This work was supported by the Academy of Finland's "Profi4 - Urban Platform for the Circular Economy (UPCE)" research funding (grant ID 318940), Academy of Finland's "Circular Economy Catalysts: From Innovation to Business Ecosystems (CICAT2025)" research funding (grant ID 320194), and the research grant that is awarded to Anil Engez by the Jenny and Antti Wihuri Foundation.

\section{REFERENCES}

Aarikka-Stenroos, L., B. Sandberg and T. Lehtimäki (2014), 'Networks for the commercialization of innovations: A review of how divergent network actors contribute', Industrial Marketing Management, 43 (3), 365-81.

Bergvall-Kareborn, B. and A. Stahlbrost (2009), 'Living lab: An open and citizen-centric approach for innovation', International Journal of Innovation and Regional Development, 1 (4), 356-70.

Bifulco, F., M. Tregua, C. C. Amitrano and A. D'Auria (2016), 'ICT and sustainability in smart cities management', International Journal of Public Sector Management, 29 (2), 132-47.

Bulkeley, H., L. Coenen, N. Frantzeskaki, C. Hartmann, A. Kronsell, L. Mai, S. Marvin, K. McCormick, F. van Steenbergen and Y. Voytenko Palgan (2016), 'Urban living labs: Governing urban sustainability transitions', Current Opinion in Environmental Sustainability, 22, 13-17. 
Bulkeley, H., S. Marvin, Y. V. Palgan, K. McCormick, M. Breitfuss-Loidl, L. Mai, T. von Wirth and N. Frantzeskaki (2018), 'Urban living laboratories: Conducting the experimental city?', European Urban and Regional Studies, 26 (4), 317-35.

Couch, C., C. Fraser and S. Percy (2003), Urban Regeneration in Europe, Oxford, UK: Blackwell.

Dell'Era, C. and P. Landoni (2014), 'Living lab: A methodology between user-centred design and participatory design', Creativity and Innovation Management, 23 (2), 137-54.

Edwards-Schachter, M. E., C. E. Matti and E. Alcántara (2012), 'Fostering quality of life through social innovation: A living lab methodology study case', Review of Policy Research, 29 (February), 672-92.

Enfield, N. J. and P. Kockelman (2017), Distributed Agency, Oxford, New York: Oxford University Press USA - OSO.

Engez, A., S. Leminen and L. Aarikka-Stenroos, (2021), 'Urban living lab as a circular economy ecosystem: Advancing environmental sustainability through economic value, material, and knowledge flows'. Sustainability, 13 (5), 2811.

Garud, R. and P. Karnøe (2003), 'Bricolage versus breakthrough: Distributed and embedded agency in technology entrepreneurship', Research Policy, 32 (2), 277-300.

Garud, R. and P. Karnøe (2005), 'Distributed agency and interactive emergence', in S. Floyd, J. Roos, C. Jacobs and F. Kellermanns (eds), Innovating Strategy Process, Malden, MA: Blackwell, pp. 88-96.

Geels, F. W. (2002), 'Technological transitions as evolutionary reconfiguration processes: A multi-level perspective and a case-study', Research Policy, 31 (8-9), 1257-74.

Geissdoerfer, M., P. Savaget, N. M. P. Bocken and E. J. Hultink (2017), 'The circular economy - a new sustainability paradigm?', Journal of Cleaner Production, 143, 757-68.

Ingstrup, M. B., L. Aarikka-Stenroos and N. Adlin (2020), 'When institutional logics meet: Alignment and misalignment in collaboration between academia and practitioners', Industrial Marketing Management, (January), 1-10.

Juujärvi, S. and K. Pesso (2013), 'Actor roles in an urban living lab: What can we learn from Suurpelto, Finland?', Technology Innovation Management Review, 3 (11), 22-7.

Koistinen, K., S. Teerikangas, M. Mikkilä and L. Linnanen (2020), 'Active sustainability actors: A life course approach', Sustainable Development, 28 (1), 208-23.

Leminen, S. and M. Westerlund (2012), 'Towards innovation in living labs networks', International Journal of Product Development, 17 (1-2), 43-59.

Leminen, S., M. Westerlund and A. Nyström (2012), 'Living labs as open-innovation networks', Technology Innovation Management Review, 2 (9), 6-11.

Liedtke, C., M. Jolanta Welfens, H. Rohn and J. Nordmann (2012), 'Living lab: User-driven innovation for sustainability', International Journal of Sustainability in Higher Education, 13 (2), 106-18.

Malila, R., S. Lehtoranta and E. L. Viskari (2019), 'The role of source separation in nutrient recovery - Comparison of alternative wastewater treatment systems', Journal of Cleaner Production, 219, $350-8$.

Manser, K., B. Hillebrand, R. Klein Woolthuis, G. W. Ziggers, P. H. Driessen and J. Bloemer (2016), 'An activities-based approach to network management: An explorative study', Industrial Marketing Management, 55, 187-99.

Markard, J., R. Raven and B. Truffer (2012), 'Sustainability transitions: An emerging field of research and its prospects', Research Policy, 41 (6), 955-67.

Mills, A. J., G. Durepos and E. Wiebe (2010), Encyclopedia of Case Study Research, Thousand Oaks, CA: Sage Publications.

Niitamo, V. P., S. Kulkki, M. Eriksson and K. A. Hribernik (2006), 'State-of-the-art and good practice in the field of living labs', paper presented at The 12th International Conference on Concurrent Enterprising: Innovative Products and Services through Collaborative Networks, ICE 2006, Milan, Italy, June 26-28, 349-57.

Sprong, N., P. H. Driessen, B. Hillebrand and S. Molner (2021), 'Market innovation: A literature review and new research directions', Journal of Business Research, 123, 450-62.

von Hippel, E. (2005), 'Democratizing innovation: The evolving phenomenon of user innovation', Journal Fur Betriebswirtschaft, 55 (1), 63-78.

Voytenko, Y., K. McCormick, J. Evans and G. Schliwa (2016), 'Urban living labs for sustainability and low carbon cities in Europe: Towards a research agenda', Journal of Cleaner Production, 123, 45-54. 
Westerlund, M. and S. Leminen (2011), 'Managing the challenges of becoming an open innovation company: Experiences from living labs', Technology Innovation Management Review, (October), 19-25. 